\title{
MORAL REASONING OF BUSINESS, NURSING AND LIBERAL ARTS STUDENTS
}

George P.W. Lan (E-mail: glan@uwindsor.ca), University of Windsor, Windsor, Ontario Sharon McMahon (E-mail: mcmaho3@uwindsor.ca), University of Windsor, Windsor, Ontario Norm King (E-mail: nking@uwindsor.ca), University of Windsor, Windsor, Ontario Fritz Rieger (E-mail: fritz@uwindsor.ca), University of Windsor, Windsor, Ontario

\begin{abstract}
This paper presents the results of an analysis of the level of moral reasoning across different majors and between undergraduate and graduate business students at a middle-sized Canadian university. The Defining Issues Test (DIT2), a recent version of the original DIT test, a well-known and widely tested psychometric instrument, is used to measure the level of moral reasoning. The results showed that beginning nursing students scored significantly lower on the DIT2 tests than the upper level liberal arts and business students and that older students scored significantly higher than younger students and that the main variable affecting the level of moral reasoning was the level of formal education of the participants. Even after allowing for the variance caused by age and by the major field of study of the respondents, the level of education by itself is a significant predictor of the P (Principled) score, an output of the DIT2, which is an indicator of the level of moral reasoning. On the other hand, the gender and political views of the respondents did not affect the DIT2 P-scores significantly.
\end{abstract}

\section{Introduction}

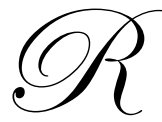

ecently, there has been an increasing emphasis on the accountability of professionals to those they serve, and a growing insistence that their behaviour meet the appropriate standards of their profession and of the community. Professions have developed codes of ethics that their members are expected to follow, and whose violation can meet with severe sanctions. While it is expected that professional accountants and nurses will follow their respective codes of ethics and act in an ethical manner in carrying out their professional duties and occupational requirements, they may do so from a variety of standpoints, such as personal convictions, religious upbringing, and legal protection.

The objective of this research is to examine the type of moral reasoning followed by business, nursing and liberal arts students in arriving at solutions to moral dilemmas. We sought to determine whether a difference exists in the moral reasoning of students who aspire to a professional career (business and nursing students) and those who are studying liberal arts subjects at university and between undergraduate and graduate students. In addition, we analysed the effect of the level of formal education, age, gender and political views on the level of moral reasoning of these students.

\section{Theoretical Development and Hypotheses}

In this study, we utilized the moral reasoning construct of Lawrence Kohlberg (1969), as modified by James Rest. Kohlberg outlined six stages of moral reasoning (See Appendix A). These ranged from an initial focus

Readers with comments or questions are encouraged to contact the authors via email. 
upon obedience and punishment as the basis of one's ethical thought processes to a mature reflection on the basis of personally held principles. Kohlberg maintained that moral development followed a certain progression from a narrow preoccupation with self to a sense of obligation to society and its rules to a sense of universal justice. He developed the Moral Judgment Interview, which was to be conducted by an expert on an individual basis in order to determine at what level an individual functioned.

James Rest and his colleagues at the University of Minnesota followed upon and developed the work of Kohlberg. Rest believed that people would come to moral judgments on the basis of the stage of development out of which they regularly thought, and that they would respond to moral dilemmas in light of their present level. In order to provide some accurate measure of that level of moral reasoning, Rest developed the Defining Issues Test (DIT), which presented participants with a series of dilemmas and a list of statements reflecting considerations to be used in arriving at a solution to the dilemmas. The output of the DIT is a continuous variable, the "P" (Principled) score. This score measures the percentage of statements chosen by the respondents that are meant to reflect the highest level of moral reasoning (i.e. stage 5 or stage 6), and is considered indicative of the level of moral reasoning in the thought processes of the participants. While Rest insisted on the importance of moral cognition or judgment and its development as essential to ethically sound behaviour, he also proposed three other components that affect the decisions made and actions taken by persons. These include moral sensitivity, moral motivation, and moral character, which encompass respectively the awareness of the effect of one's actions upon others, the importance given to moral values, and strength of conviction and courage (Rest and Narvaez, 1994).

Since its inception in 1979, the DIT test has been rigorously tested and is considered by many to be a reliable and valid measure (Jeffrey, 1993). It has been widely administered to a large variety of groups worldwide, representing an extensive sampling of persons of varied kinds and levels of education and diverse professions. The data gathered by James Rest (1979) showed a progression in moral reasoning. He reported that over 50 studies supported the general tenet that moral judgment increases 10 points with each level of education. Kohlberg's model maintains that an individual's moral development may level off but does not drop to lower levels. Some studies have also maintained that, in addition to improved scores with increased education and over time, there is a consistent relationship between DIT measures and ethical behaviour (Ponemon and Gabhart, 1994; Rest, 1986; and Rest and Narvaez, 1994). Other studies, however, have suggested that DIT P-Scores do not necessarily match the manner in which real life decisions are made (Reall et al., 1998). Bearing in mind these considerations, results do need to be interpreted with some caution.

\section{Hypotheses}

The hypotheses are formulated according to the expectations arising from prior research investigating the level of moral reasoning of students as well as other populations such as accountants, managers and alumni and also taking into consideration the Canadian environment.

H1: The P scores for graduate students will be higher overall than the scores for undergraduate students.

Cumulative studies using the DIT have consistently shown that the level of formal education and age are the most decisive factors in the development of moral judgment as assessed by the Rest schema (Rest, 1984), with level of education carrying the greater weight (noted in St. Pierre et al. 1990 and Jeffrey, 1993).

H2: The P scores for undergraduate liberal arts students will be higher than the scores for undergraduate business and nursing students.

One can argue that only a conventional level of moral conviction (stage 3 and stage 4 ) is necessary for business and nursing students. Professional accountants and nurses abide by the rules, regulations and professional codes of their professions. On the other hand, the increasingly higher level of public expectation of business professionals and accountants, in particular, indicates that higher levels of moral reasoning may be expected of them. Results of previous surveys have indicated that, while student scores in all areas of study increase with their level of formal education, students in liberal arts programs tend to score higher than others when DIT tests are administered 
in the beginning years of a program. (St Cloud State University, Fund for the Improvement of Postsecondary Education, U.S. Department of Education, 1993, website) Ponemon and Glazer (1990) found that, among accounting programs, students and alumni from institutions with liberal arts emphasis had higher DIT scores. At the senior level, however, Jeffrey (1993) found that there was no appreciable difference in scores between accounting, other business, and liberal arts majors.

H3: The scores for nursing students will be higher than those of the undergraduate business students.

One factor that may affect the level of moral reasoning in the nursing field of study is the early introduction to nursing students of a Code of Ethics and a legislated Standards of Practice in Canadian universities whereas ethics are usually introduced later in the business curriculum. At the same time, Rest has observed that a sustained study of ethics of some weeks' duration is essential to an appreciable increase in the DIT P scores. (St. Pierre et al. 1990).

H4: $\quad$ The P scores for older students will be higher than those of younger students.

Once again, the impact of age on DIT scores may be recalled and we expect that older students will, on average, have higher $\mathrm{P}$ scores than younger students. A factor to consider in this matter is the degree to which the age or program has a greater bearing on the DIT score in our sampling; to determine, for example, whether older students in undergraduate business programs will have higher or lower scores than younger students enrolled in liberal arts.

H5: The P scores for female students will not differ appreciably from those of male students.

Overall, the results of tests on men and women have not resulted in any significant difference in their principled scores, with women showing a slightly higher result than men. (Thoma, 1986) Citing numerous accounting and business ethics studies, however, Cohen, Pant, and Sharp (1998) concluded that gender had a significant effect on moral reasoning, and that women had a decidedly higher level of moral reasoning than men. According to their hypothesis, "women respondents are more likely to evaluate questionable actions as less ethical and are less likely to state that they would perform the action than male respondents." Recalling Carol Gilligan's emphasis that women determine moral behaviour more on the basis of an ethics of caring than of justice, in contrast to Rest who argues that men and women develop moral understanding at approximately the same rate, Bay (1999) and Bay and Greenberg (2001), conclude that "no concrete empirical evidence has been found that supports either position." At the same time, the higher levels of reasoning suggested by Rest are purportedly shaped by the degree to which the respondents are aware of and take into responsible account the social context within which they decide and act (Bebeau, 2001).

H6: Respondents who categorize themselves as liberal are more likely to attain higher DIT scores than those who name themselves as conservative.

There is some indication that those who regard themselves as politically conservative score lower on the test than those who see themselves as more liberal. Fisher and Sweeney (1998) do see this ideological bias, but also affirm that it may be somewhat corrected when subjects are asked to identify the statements representing the highest level of moral development rather than merely to state their preference.

\section{Research Method}

The methodological instrument used for this research is the Defining Issues Test, developed and further revised by the late James Rest of the University of Minnesota Centre for the Study of Ethical Development. According to Rest, moral judgment is "the process by which a person arrives at a judgment of what is a moral thing to do in a moral dilemma" (Guide to Defining Issues Test, p. 18). Rest drew upon and refined the earlier work of Kohlberg who defined six stages of moral development. In this study, we used the DIT2 version of the Defining Issues Test, which is an updated revision of the original DIT. The DIT2 test is a pencil and paper questionnaire containing 5 
ethical dilemmas. For each of the dilemmas, various issues are outlined and the respondents are asked to rate and rank the issues in terms of importance in making their decisions. Additional information is collected on age, gender, level of formal education and political views.

Our sampling involved a cross-section of students in a number of programs (undergraduate business, MBA, economics, nursing and liberal arts) at the University of Windsor, a middle-sized Canadian university. A short description of the research study was made in selected classes and a package containing the DIT2 test and a consent form was given to students volunteering to participate in the study. A certificate of participation was handed out to the respondents when they returned the completed questionnaires. The questionnaires were coded and sent to the University of Minnesota Centre for the Study of Ethical Development for preliminary statistical analysis.

Among the 170 students who voluntarily completed the DIT2 questionnaire, with five ethical dilemmas, were 141 undergraduate and 29 graduate students, the latter all registered in the Master's program in business administration (MBA). The DIT2 scoring procedure calculates an M (meaningless) score and performs a consistency test on the respondents' questionnaires; subjects who failed these two tests are purged from the sample. Accordingly, data from 17 participants (representing 10.0\%) were excluded from the subsequent analysis, yielding a total sample size of 153 valid responses. This sample consisted of 31 undergraduates enrolled in upper level liberal arts courses, 51 undergraduates in their junior and senior years in business administration and economics (34 business with non-accounting major, 8 business with accounting major and 9 economics), 26 enrolled in the MBA program and 45 beginning students in nursing.

Various means and standard deviations were computed as reported in tables 1 and 2 below. To determine which means are significantly different from each other, Tukey's tests were conducted. A correlation analysis was performed to measure the bivariate relationships of the various variables and to assess potential multicollinearity among the independent variables. Ordinary least squares regression analysis was used to determine the significance and contribution of the variables in predicting the P-Scores for the entire sample. Univariate analysis-of-variance models were also computed to determine the significance of main effects, interaction effects and the effect of covariates on the fixed factor.

\section{Results}

Table 1 provides information on the mean age, level of formal education, political views of the major fields of study of the respondents. In addition the number of males and females in each of the four fields of study are shown. The mean age of the nursing students (21.64) appeared to be high for a first semester nursing course indicating that there was a substantial number of mature students entering the nursing program. The mean age of the liberal arts students was the highest, indicating that there could be a substantial proportion of part-time, mature students in the liberal arts sample. More than two thirds of the respondents (105 of 149) were female.

Table 2 presents information on the mean DIT2 P-Scores and standard deviations by major (Panel A), level of formal education (Panel B), age (Panel C), gender (Panel D) and political views (Panel E). As shown in Panel A, the mean P Score for the beginning nursing students (21.11) was much lower than the mean score of the students in the other 3 majors. Panel B shows that mean P scores of the freshman and sophomore level students were much lower than those of the other two groups. Similarly, the mean P-scores for those under 22 was less than that of the over 22 group by a large margin as shown in Panel C. In Panels D and E, the differences in the mean P-Scores between the male and female participants and among the various categories of political views are not substantial. 
Table 1: Mean age, level of education, political views and gender distribution of respondents

\begin{tabular}{|l|c|c|c|c|c|}
\hline \multicolumn{1}{|c|}{ Major } & $\begin{array}{c}\text { Mean Age } \\
\text { (in years) }\end{array}$ & $\begin{array}{c}\text { Mean Level of } \\
\text { Education* }\end{array}$ & $\begin{array}{c}\text { Mean Political } \\
\text { Views** }\end{array}$ & $\begin{array}{c}\text { Male } \\
\text { Respondents }\end{array}$ & $\begin{array}{c}\text { Female } \\
\text { Respondents }\end{array}$ \\
\hline Liberal Arts & $\begin{array}{c}30.61 \\
(\mathrm{n}=31)\end{array}$ & $\begin{array}{c}7.96 \\
(\mathrm{n}=28)\end{array}$ & $\begin{array}{c}2.29 \\
(\mathrm{n}=31)\end{array}$ & 5 & 26 \\
\hline Business \& Economics & $\begin{array}{c}22.96 \\
(\mathrm{n}=49)\end{array}$ & $\begin{array}{c}8.94 \\
(\mathrm{n}=49)\end{array}$ & $\begin{array}{c}2.73 \\
(\mathrm{n}=51)\end{array}$ & 25 & 24 \\
\hline Nursing & $\begin{array}{c}21.64 \\
(\mathrm{n}=44)\end{array}$ & $\begin{array}{c}6.32 \\
(\mathrm{n}=44)\end{array}$ & $\begin{array}{c}2.67 \\
(\mathrm{n}=45)\end{array}$ & 3 & 11 \\
\hline MBA & $\begin{array}{c}27.42 \\
(\mathrm{n}=26)\end{array}$ & $\begin{array}{c}10.08 \\
(\mathrm{n}=26)\end{array}$ & $\begin{array}{l}2.88 \\
(\mathrm{n}=26)\end{array}$ & 44 & 14 \\
\hline Total & 24.93 & $\begin{array}{c}2.17 \\
(\mathrm{~N}=147)\end{array}$ & & 105 \\
\hline
\end{tabular}

In the above table, $\mathrm{N}$ represents the number of respondents in each major. Four respondents did not indicate their gender.

*Codes used for Level of Education:

$6=$ Freshman in college in bachelor degree program

7 = Sophomore

8 = Junior

$9=$ Senior

$10=$ Professional degree e.g. M.B.A

11 = Masters degree (in academic graduate school)

$12=$ Doctoral degree $($ e.g. $\mathrm{PhD})$

**Codes used for political views

1 = Very liberal

2 = Somewhat liberal

3 = Neither liberal nor conservative

4 = Somewhat Conservative

$5=$ Very conservative

Table 2: Mean DIT2 P-Scores

Panel A-By Major Field of Study

\begin{tabular}{|l|c|c|c|}
\hline Major Field of Study & N & Mean & Std. Dev. \\
\hline Liberal Arts & 31 & 35.32 & 12.33 \\
\hline Business \& Economics & 51 & 31.9 & 11.53 \\
\hline Nursing & 45 & 21.11 & 12.17 \\
\hline MBA & 26 & 35.62 & 11.43 \\
\hline TOTAL & 153 & 30.05 & 13.19 \\
\hline
\end{tabular}

Panel B-By Educational Level

\begin{tabular}{|l|c|c|c|}
\hline Education Level & N & Mean & Std. Dev. \\
\hline Freshman \& Sophomore & 50 & 21.24 & 12.09 \\
\hline Junior and Senior & 69 & 33.57 & 11.88 \\
\hline Graduate student & 28 & 35.72 & 11.27 \\
\hline TOTAL & 153 & 29.78 & 13.30 \\
\hline
\end{tabular}

Panel C-By Age*

\begin{tabular}{|l|c|c|c|}
\hline Age & N & Mean & Std. Dev. \\
\hline 22 and under & 84 & 26.25 & 12.14 \\
\hline Over 22 & 66 & 35.25 & 12.83 \\
\hline TOTAL & 150 & 30.21 & 13.20 \\
\hline
\end{tabular}

Panel D-By Gender

\begin{tabular}{|l|c|c|c|}
\hline Gender & N & Mean & Std. Dev. \\
\hline Female & 105 & 29.17 & 13.66 \\
\hline Male & 44 & 31.43 & 11.87 \\
\hline TOTAL & 149 & 29.84 & 13.16 \\
\hline
\end{tabular}


Table 2 (Cont'd)

Panel E- By Political Views

\begin{tabular}{|l|c|c|c|}
\hline Political views & N & Mean & Std. Dev. \\
\hline Very Liberal & 11 & 30.55 & 11.77 \\
\hline Somewhat liberal & 64 & 31.27 & 11.27 \\
\hline Neither & 47 & 28.55 & 14.81 \\
\hline Somewhat conservative & 30 & 29.22 & 15.08 \\
\hline Very Conservative & 1 & 42.00 & 13.19 \\
\hline TOTAL & 153 & 30.05 & \\
\hline
\end{tabular}

*For the purpose of this analysis only, the students were grouped into 2 categories (22 and under and over 22 years old). In all other tests in this paper regarding the age variable, the actual age of the respondents in years was used.

In order to determine whether there was a significant difference between any two mean DIT2 P-Scores reported for the different major fields of study and level of education in Table 2, Post Hoc Tukey tests were conducted. The results, shown in Table 3, indicate that the mean P-Score for beginning nursing students was statistically different from those of the other three major fields of study. Similarly the mean P-Scores of the freshmen and sophomores were significantly lower than those of the other two groups.

Table 3: Post Hoc Tukey HSD tests with P-Score as Dependent Variable

Panel A --- Major

\begin{tabular}{|ll|c|c|}
\hline (I)Major & (J) Major & Mean Difference (I-J) & Level of Significance \\
\hline Liberal Arts & Bus \& Econ & 3.421 & 0.587 \\
& Nursing & $14.212^{*}$ & 0.000 \\
& MBA & -0.299 & 1.000 \\
\hline Business \& Economics & Liberal Arts & -3.4206 & 0.587 \\
& Nursing & $10.791 *$ & 0.000 \\
& MBA & -3.719 & 0.564 \\
\hline Nursing & Liberal Arts & $-14.212^{*}$ & 0.000 \\
& Bus \& Econ & $-10.791 *$ & 0.000 \\
& MBA & $-14.510^{*}$ & 0.000 \\
\hline MBA & Liberal Arts & 0.299 & 1.000 \\
& Bus \& Econ & 3.720 & 0.564 \\
\hline
\end{tabular}

* The mean difference is significant at the 0.001 level.

Panel B --- Education Level

\begin{tabular}{|c|c|c|c|}
\hline (I) Education & (J) Education & Mean Difference (I-J) & Level of Significance \\
\hline Fresh. \& Sophomore & $\begin{array}{l}\text { Junior \& Senior } \\
\text { MBA }\end{array}$ & $\begin{array}{l}-12.325^{*} \\
-14.480^{*}\end{array}$ & $\begin{array}{l}0.000 \\
0.000\end{array}$ \\
\hline Junior \& Senior & $\begin{array}{l}\text { Fresh. \& Sophomore } \\
\text { MBA }\end{array}$ & $\begin{array}{l}12.325^{*} \\
-2.154\end{array}$ & $\begin{array}{l}0.000 \\
0.696\end{array}$ \\
\hline MBA & $\begin{array}{l}\text { Fresh. \& Sophomore } \\
\text { Junior \& Senior }\end{array}$ & $\begin{array}{c}14.480 * \\
2.154\end{array}$ & $\begin{array}{l}0.000 \\
0.696\end{array}$ \\
\hline
\end{tabular}

* The mean difference is significant at the 0.01 level.

Table 4 presents the results of correlation analysis. Education and age were highly correlated with the dependent variable, P-Score. There was also significant correlation between education and age and level of education and gender (at the .01 level of significance) and also between age and major and political views and major (at the .05 level of significance). The highest correlation coefficient between any two independent variables is 0.33 . To determine whether multicollinearity was a serious problem for this study, variance inflation factors (see table 5) were computed in the regression analysis; if they exceed 10, multicollinearity might be present. 
Table 4. Correlation matrix

\begin{tabular}{|l|c|c|c|c|c|c|}
\hline \multicolumn{1}{|c|}{ Variable } & P-Score & Major & Education & Age & Gender & Political Views \\
\hline P-Score & 1.00 & & & & & \\
\hline Major & -0.14 & 1.00 & & & & \\
\hline Education & $0.46^{* *}$ & 0.10 & 1.00 & & & \\
\hline Age & $0.41^{* *}$ & $-0.16^{*}$ & $0.33^{* *}$ & 1.00 & & \\
\hline Gender & 0.08 & 0.02 & $0.32^{* *}$ & -0.05 & 1.00 & \\
\hline Political Views & -0.05 & $0.18^{*}$ & 0.09 & -0.02 & -0.06 & 1.00 \\
\hline
\end{tabular}

* Correlation is significant at the 0.05 level (2-tailed)

***Correlation is significant at the 0.01 level (2-tailed)

The results of multiple linear regression analysis of the total sample with P-score as the dependent variable are shown in Table 5. The level of education and age of the respondents were significant predictors of P-Score. The level of education had the highest standardised coefficient and was the most significant one in explaining the P-score of the respondents.

Variance inflation factors were less than 1.5; thus indicating that multicollinearity was not a serious problem in this regression analysis and that the estimated regression coefficients had not been distorted.

Table 5. Regression Analysis - Dependent variable is P-Scores of Entire Sample

\begin{tabular}{|l|c|c|c|c|c|}
\hline \multicolumn{1}{|c|}{ Predictors } & $\begin{array}{c}\text { Unstandardised } \\
\text { coefficient }\end{array}$ & $\begin{array}{c}\text { Standardized } \\
\text { coefficient (Beta) }\end{array}$ & T-statistic & $\begin{array}{c}\text { Sig. } \\
\text { (p-value*) }\end{array}$ & $\begin{array}{c}\text { Variance } \\
\text { Inflation Factor }\end{array}$ \\
\hline Education & 3.204 & 0.383 & 4.592 & $0.000^{* *}$ & 1.298 \\
\hline Age & 0.452 & 0.263 & 3.344 & $0.001^{* *}$ & 1.152 \\
\hline Gender & -0.840 & -0.029 & -0.375 & 0.709 & 1.155 \\
\hline Political Views & -0.789 & -0.053 & -0.729 & 0.468 & 1.017 \\
\hline Constant & -5.256 & & -0.890 & 0.375 & \\
\hline
\end{tabular}

*p-values are for 2-tailed test

** Significant at $5 \%$ level

$\mathrm{N}=139$

R-Square $=0.276$

Adjusted R-Square $=0.255$

Level of Education and political views were coded as in the footnotes to Table 1. For the age variable, the actual age of the respondents in years was used. The gender variable was coded as follows: females $=0$ and male $=1$.

To test the significance of the effect of the level of education and the major field of study on the DIT2 PScores, univariate ANOVA tests were conducted with these two variables as the main effects. Panel A of Table 6 shows that level of education was significant at the $10 \%$ level whereas the major field of study was not and that the interaction effect between the two variables was not significant. Panel B shows that the level of education was significant at the 5\% level but gender was not and there was no interaction effect between the two variables. Note here that the various levels of education were consolidated in three groups: freshman and sophomore, junior and senior and graduate student.

To determine the impact of the variance in the age of the respondents on the significance of the level of education, univariate ANOVA tests with P-Score as the dependent variable and level of education as the fixed factor was conducted using the actual age of the respondents as a covariate variable. As shown in Panel A of Table 7, the level of education was significant, indicating even after taking out the variance caused by the age of the respondents, the level of education remained a significant predictor of the DIT2 P-Scores. Panel B of Table 7 shows that with the major field of study as a covariate variable, the level of education remained a significant explanatory factor. 
Table 6. Panel A-Main Effects: Education and Major Field of Study

\begin{tabular}{|l|c|c|c|}
\hline & DF & F-Value & Significance of F \\
\hline Education* & 2 & 2.871 & 0.060 \\
\hline Major** & 3 & 0.367 & 0.777 \\
\hline Interaction (Education X Major) & 2 & 1.410 & 0.248 \\
\hline
\end{tabular}

*Level of Formal Education coded as follows:

1 = Freshman and sophomore; 2 = Junior and senior; 3 = Graduate student

**Major code as follows:

$1=$ Liberal Arts; 2 = Business and Economics; $3=$ Nursing; $4=$ MBA

Panel B-Main Effects: Education and Gender

\begin{tabular}{|l|c|c|c|}
\hline & DF & F-Value & Significance of F \\
\hline Education & 2 & 9.287 & 0.000 \\
\hline Gender & 1 & 0.827 & 0.365 \\
\hline Interaction (Education X Gender) & 2 & 0.449 & 0.639 \\
\hline
\end{tabular}

Table 7. Univariate Analysis of Variance with P-Score as dependent variable and Level of Education as the fixed factor.

Panel A-Age of respondents in years as a covariate

\begin{tabular}{|l|c|c|c|}
\hline \multicolumn{1}{|c|}{ Source } & DF & F-Value & Significance of F \\
\hline Corrected Model & 3 & 18.686 & 0.000 \\
\hline Intercept & 1 & 29.232 & 0.000 \\
\hline Age (covariate) & 1 & 13.000 & 0.000 \\
\hline Education* & 2 & 13.450 & 0.000 \\
\hline
\end{tabular}

Panel B-Major of respondents as a covariate

\begin{tabular}{|l|c|c|c|}
\hline \multicolumn{1}{|c|}{ Source } & DF & F-Value & Significance of F \\
\hline Corrected Model & 3 & 15.261 & 0.000 \\
\hline Intercept & 1 & 76.811 & 0.000 \\
\hline Major (covariate) & 1 & 4.654 & 0.033 \\
\hline Education & 2 & 21.644 & 0.000 \\
\hline
\end{tabular}

* Education was coded as in Table 6.

\section{Discussion of Results}

The results of the multiple linear regression analysis in Table 5 show that the level of education is a significant predictor of P-Scores, thus supporting Hypothesis 1, which predicts that the P-Scores for graduate students will be higher overall than those of the undergraduate student. When examining the P-Scores of the business, nursing and liberal arts students, it would appear that the older average age of the liberal arts students (approximately 30 years) compared to that of the graduate students (approximately 27 years) narrowed the difference between their DIT-2 Pscores. Had we had a larger sampling of lower level, younger liberal arts students, there might have been a larger discrepancy between liberal arts and graduate students rather than a virtually identical result.

Hypothesis 2, which predicts that the P- Scores for undergraduate liberal arts will be higher than those of undergraduate business and nursing students, is partially verified and partially rejected. The liberal arts students did score significantly higher than the nursing students but their mean age was approximately nine years older than that of the nursing students and they had a mean level of education of "junior' versus slightly above "freshman" for the nursing students. In this sense the expectations are validated. At the same time, the business and economics students were younger by approximately seven and one half years (22.96 years versus 30.61 years), as shown in Table 1. Yet the business students were primarily at the senior level compared to the junior level for the liberal arts students. The mean P-score of the business students was only a little lower (31.90 to 35.32), as shown in Panel A of Table 2. Hence, there are two offsetting factors here: the higher age level of the liberal arts students and the higher 
education level of the business students. It would appear that, after allowing for age difference and field of study, that liberal arts students in our survey scored, slightly but not appreciably higher than business students when all factors are considered.

Students in business and economics at the University of Windsor are required to take a large number of non-business courses, approximately $40 \%$ non-business. This factor could partially explain why there is no significant difference between the P-Scores of liberal arts students and those of the business and economics students.

Hypothesis 3, which predicts that the P-Scores of nursing students, will be higher than those of the undergraduate business students is rejected insofar as nursing students scored lower than undergraduate liberal arts and business students. In this instance, however, the deciding factor seems to be the education level of the nursing students, virtually all of whom were in the freshman year of their program.

Hypothesis 4, which postulates that the $\mathrm{P}$-Scores of older students will be higher than those of the younger students, is supported by the results of the linear regression analysis in Table 5, where the age variable is a significant predictor of the P-Scores. The DIT2 P-Scores of the nursing students were significantly lower than those of the other groups with higher mean ages.

There was no gender effect in this study as shown in Table 5. This finding does not reject Hypothesis 5, which states that the P-Scores for female students will not differ appreciably from those of male students. Hypothesis 6, which predicts that respondents with more liberal political views will score higher DIT2 P-Scores than those with more conservative views, is not supported in this study (see Table 5). No significant difference was detected between the various categories of political views.

\section{Summary and Conclusions}

An important conclusion of this study is that the DIT P-scores increase as the level of formal education of the students increases, indicating a greater level of moral reasoning with more advanced education. In terms of age, one would also hope that some degree of wisdom would come with increased years, and that moral sensitivity and more integrated and principled thought processes would be integral to that maturity. Our results do not show that the field of study, gender and political views affect the level of moral reasoning of students in a middle-sized Canadian university.

In real life situations, many other factors could enter into play that might affect how individuals actually reflect on and behave when facing ethical dilemmas. In such situations where one's own convictions and livelihood may be engaged in very practical and existential ways, where personal and family needs, as well as fears, may be vividly present, the actual decision reached may be different from what one might ideally wish for. What is morally correct in an abstract or hypothetical situation and what is humanly possible in a concrete real life situation may not coincide. Hence, the complexity and greater ambiguity of real life situations may impose limits on what might be indicated by the P-Score of a DIT2 test completed in a personally safe situation, where one's hypothetical answers do not have personal consequences.

It is difficult to make strong conclusions from a limited study such as this. Nevertheless, this study is among the first reported ones using the new DIT2 and the findings make a contribution to the limited studies that have been conducted in the Canadian environment. Further research could investigate the level of moral reasoning of lower and upper level students in business and nursing and compare their level of moral reasoning with those of accounting and nursing practitioners.

\section{Acknowledgements}

The authors acknowledge the contributions of Jang Singh, Luke Shannon, Chike Okechuku and John Dickinson to this project and thank the many students who volunteered their time in completing the DIT2 questionnaires. We are also grateful for financial support from the Odette School of Business. 


\section{References}

1. Abdolmohammadi, M. and R. J. McQuade. 2002. Applied Research in Financial Reporting: Text and Cases. McGraw-Hill, New York, NY.

2. Bay, D. D. 1999. "What is the DIT? Critical Perspectives in Accounting Conference". http://panopticon.csustan.edu/cpa99/html/bay.html.

3. Bay, D. D. and R. R. Greenberg. 2001. "The relationship of the DIT and behavior: A replication". Issues in Accounting Education, 16 (3): 367-380.

4. Bebeau M. J. 2001. "Influencing the moral dimensions of professional practice: Implications for teaching and assessing for research integrity. Proceedings: Investigating Research integrity". http://ori.dhhs.gov/multimedia/acrobat/papers/bebeau.pdf.

5. Cohen J. R., L.W. Pant and D.J. Sharp. 1998. "The effect of gender and Academic discipline diversity on the ethical evaluations, ethical intentions and ethical orientation of potential public accounting recruits". Accounting Horizons. Vol. 12, No. 3, pp. 250-270.

6. Fisher D. and J. Sweeney. 1998. "The relationship between political attitudes and moral judgement: Examining the validity of the Defining Issues Test”. Journal of Business Ethics, Vol. 17, pp. 905-916.

7. Jeffrey, C.1993. "Ethical development of accounting students, non-accounting business students, and liberal arts students". Issues in Accounting Education, 8 (1): 86-96.

8. Ponemon L. A. and D.R. L. Gabhart. 1993. “Auditors' ethical reasoning: A comparison of firms in Canada and the United States". Research Monograph No. 21, Chapter 4, Vancouver, B.C. CGA - Canada Research Foundation.

9. Ponemon and Glazer. 1990. "Accounting education and ethical development: The influence of liberal learning on students and alumni in accounting practice". Issues in Accounting Education (Fall): pp. 195208.

10. Rest J. 1979. Defining Issues Test. Minneapolis, Minn.: University of Minnesota Press.

11. Reall, M., Bailey, J. and Stoll, S. 1998. "Can ethics be taught in accounting?" Journal of Accounting Education, Vol. 11, pp. 185-209.

12. Rest J. 1984. "The major components of morality". Morality, Moral Behavior, and Moral Development (NewYork: Wiley), W. Kurtines and J. Gerwitz (Eds.) p.p.24-40.

13. Rest, J. 1986. Moral development: Advances in research and theory ( New York: Praeger).

14. Rest J. and D. Narvaez. 1994. "Background: Theory and Research". Moral Development in the Professions, pp. 1-26.

15. St. Cloud University, Fund for the Improvement of Postsecondary Education, U.S. Department of Education, 1993

16. http:/www.ed.gov/offices/OPE/FIPSE/LessonsII/stcloud.html.

17. St. Pierre, K ., Nelson E. and Gabbin, A. 1990. "A study of the ethical development of accounting majors in relation to other business and nonbusines disciplines". The Accounting Educators Journal. Vol. 3 (1) pp23-35.

18. Thoma, S.J. 1986. "Estimating gender differences in the comprehension and reference of moral issues". Developmental Review 6: pp.165 -180. 


\section{Appendix A.}

Kohlberg's Stage Model of Ethical Cognition

\begin{tabular}{|l|l|l|l|}
\hline Level & Stage & Action & Reason for Action \\
\hline \multirow{2}{*}{ I. Preconventional } & 1 & Avoid breaking rules & Avoid punishment \\
\cline { 2 - 4 } & 2 & Follow rules & Serve own self-interest \\
\hline \multirow{3}{*}{ 2. Conventional } & 3 & $\begin{array}{l}\text { Group membership (do what is ex- } \\
\text { pected by others) }\end{array}$ & $\begin{array}{l}\text { Need to be accepted as a good person in } \\
\text { the eyes of group members }\end{array}$ \\
\hline \multirow{2}{*}{ 3. Post-conventional } & 4 & Obey laws, rules, and obligations & Keep social institutions going \\
\cline { 2 - 4 } & 5 & Upholding nonrelative obligation first & Obligation to law \\
\hline
\end{tabular}

Source: Adapted from L. Kohlberg, "Stages and Sequences: The Cognitive Developmental Approach to Socialization," in D. Goslin (ed.), Handbook of Socialization Theory and Research (Chicago:Rand McNally, 1969).

In the Kohlberg model, each of the stages is viewed as qualitatively higher than the previous stages in terms of ethical reasoning. Stage 1 and stage 2 belong to the pre-conventional level, characterized by the principle of self-interest and the ethics of convenience. At stage 1, the individual is self-centred and avoids breaking rules in order to avoid punishment. Stages 3 and 4 belong to the conventional level, which is the ethics of conformity. An individual at stage 3 does what is expected by the group while in stage 4 , the individual obeys civic and/or religious laws, rules and regulations, and professional codes because he or she believes in the importance of obeying such laws, not just for the acceptance of peer groups. The last two stages 5 and 6 belong to the Post-conventional level, where the individual acts out of the ethics of conviction. At stage 5, the individual has achieved the ethics of conviction and acts according to the ethics of some high-order ethical principle such as utilitarianism. In the final stage 6 , the individual follows the ethics of unwritten global ethical principles, such as the principles of justice, duties, and equal human rights.

Source: Abdolmohammadi and McQuade, 2002, pp.221-222. 
Notes 